\title{
Chromosomal Aberrations and Apomictic Behavior in Two Cytotypes of Pteris cretica L. from Western Himalayas
}

\author{
Manjit Inder Singh Saggoo and Mandeep Kaur* \\ Department of Botany, Punjabi University, Patiala-147002, Punjab, India \\ Received April 28, 2016; accepted January 7, 2017
}

\begin{abstract}
Summary Plants of Pteris cretica L. were collected from four different forests of Himachal Pradesh, India to know the chromosome variability and reproductive status of the species. In the study area, two cytologic forms, diploid $(2 n=58)$ and triploid $(2 n=87)$, of $P$. cretica are met with. The triploid cytotype is uncommon in distribution. Both the cytotypes are apogamous in nature. Meiotic analysis of different accessions of $P$. cretica revealed that meiotic course was highly irregular with reduced spore fertility. High incidence of micronuclei in triploid cytotype is a conspicuous phenomenon among other meiotic abnormalities. Variations in spore size and shape have been observed during spore studies. The present count of one B-chromosome $(3 n=87+1 \mathrm{~B})$ in triploid apogamous form is the first report of $\mathrm{B}$-chromosome in the species.
\end{abstract}

Key words Pteris, Apomixis, Meiotic abnormality, Microsporogenesis, B-chromosome, Fern.

Pteris is a cosmopolitan genus in the imperishable family Pteridaceae of more than 250 species distributed in wide geographical areas (Copeland 1947). Cytologically, Pteris is one of the best known fern genera with phenomenon like polyploidy, apogamy and hybridization playing important role in its speciation (Chao et al. 2012). A number of species exhibit intraspecific cytotypes-diploids, triploids, tetraploids, octoploids, etc. Manton (1950) was the first to report polyploidy and apogamy in the genus. In $P$. cretica L., one of the important species, besides morphological variation diploid, triploid and tetraploid apogamous taxa has been reported (Walker 1962, 1979, 1992, Mitui 1965, Nakato 1975, 1989, Suzuki and Iwatsuki 1990). Natural hybridization is quite common in the species (Nakaike 1984, Huang et al. 2011). The species is widely distributed in tropical and warm temperate regions of the old world (Kramer and McCarthy 1998). In India, the species has been collected by different workers from forests of western and central Himalayas.

The present study was carried out on plants of $P$. cretica collected from four different forests of Himachal Pradesh to know the reproductive status of the species. An attempt has been made to explore the presence of intraspecific variability, if any, in morphological, cytological and reproductive characteristics. The species has been reported to exist in both sexual as well as apogamous forms.

\footnotetext{
* Corresponding author, e-mail: mandeepbot@gmail.com DOI: $10.1508 /$ cytologia. 82.161
}

\section{Materials and methods}

Wild taxa of Pteris cretica L. were collected from Himachal Pradesh during monsoons (July to September) for this study. Voucher specimens were deposited at Herbarium, Department of Botany, Punjabi University, Patiala (PUN). To obtain spore mother cells (SMCs) undergoing meiosis, fronds with young sporangia were fixed in Carnoy's fixative $[(6: 3: 1)$ alcohol: chloroform: glacial acetic acid, v/v/v] for $24 \mathrm{~h}$ at room temperature and then transferred to $70 \%$ alcohol and stored under refrigeration until use. To study meiotic course, spore mother cells were squashed in $1 \%$ acetocarmine. Observations on number of spores per sporangium were made following the procedure suggested by Huang et al. (2011). Ten sporangia from each sporophyte were randomly sampled. The average size of spores was estimated from normallooking, well-stained spores. Photographs were taken with a Nikon 80 i eclipse microscope.

\section{Results}

In the study area, two cytologic forms of Pteris cretica L. are met with. The information regarding the exact place of collection, chromosome number, ploidy level, abnormalities, etc. is provided in Table 1. The inferences on the breeding system is mostly based on spore output; the apogamous ones have 16-32 spores per sporangium. Cytological examination of the species collected from Shimla $(2100 \mathrm{~m})$, Kangra $(680 \mathrm{~m})$ and Dalhousie $(1435 \mathrm{~m})$ showed the diploid cytotypes, whereas the specimen examined from Dalhousie $(1720 \mathrm{~m})$ was triploid.

Morphological studies revealed that diploid and trip- 
Table 1. Locality with altitude, voucher specimen, chromosome number, ploidy level and percentage of meiotic abnormalities in two cytotypes of Pteris cretica L. of family Pteridaceae.

\begin{tabular}{|c|c|c|c|c|c|c|c|c|c|c|c|}
\hline \multirow{2}{*}{$\begin{array}{l}\text { Localities with } \\
\text { altitude }(\mathrm{m})\end{array}$} & \multirow[b]{2}{*}{ PUN* } & \multirow{2}{*}{$\begin{array}{l}\text { C.No. } \\
(n)\end{array}$} & \multirow{2}{*}{$\begin{array}{l}\text { Ploidy } \\
\text { level }\end{array}$} & \multicolumn{8}{|c|}{ Abnormal SMCs \% } \\
\hline & & & & Stickiness & $\begin{array}{l}\text { Unoriented } \\
\text { bivalents }\end{array}$ & Laggards & Bridges & $\begin{array}{c}\text { Interbivalent } \\
\text { connections }\end{array}$ & Micronuclei & Triad & Polyad \\
\hline $\begin{array}{l}\text { HP: Kangra, Ranital } \\
\quad(680 \mathrm{~m})\end{array}$ & 4840 & 58 & Diploid & 75.00 & - & 26.53 & 18.36 & 40.81 & 10.20 & - & - \\
\hline $\begin{array}{l}\text { HP: Kullu, Raison } \\
\quad(1435 \mathrm{~m})\end{array}$ & 4841 & 58 & Diploid & 60.52 & 10.16 & 30.89 & 20.50 & 21.67 & 13.55 & - & - \\
\hline $\begin{array}{l}\text { HP: Shimla, Summer } \\
\text { Hill }(2100 \mathrm{~m})\end{array}$ & 4839 & 58 & Diploid & 80.85 & - & 29.16 & 19.44 & 26.38 & 11.11 & - & - \\
\hline $\begin{array}{l}\text { HP: Dalhousie, Bathri } \\
\qquad(1720 \mathrm{~m})\end{array}$ & 4842 & 87 & Triploid & 31.81 & 9.63 & 19.27 & 14.45 & - & 30.12 & 7.22 & 13.25 \\
\hline
\end{tabular}

$\mathrm{PUN}^{*}=$ Accession number Herbarium code of Department of Botany, Punjabi University, Patiala, C. No.=Chromosome number, SMC $=$ Spore mother cell, $\mathrm{HP}=$ Himachal Pradesh.

loid cytotypes are comparatively alike. Sterile pinnae are lance shaped, and fertile pinnae are narrow and simple or forked at the tip. It has arching pinnate fronds with five pinnae. Linear sori are present at margin ends beneath the pinnae surface, which curl up in order to protect them.

\section{Diploid}

Our studies involved the investigation of accessions collected from three different localities of Himachal Pradesh (Table 1). Meiotic course illustrates the presence of 58 bivalents at M-I in all three taxa (Fig. 1). These are diploid with $2 n=58$. All the plants examined from these three localities are apomicts producing 16-32 spores per sporangia.

The accession collected from Shimla (2100m) showed the highest incidence of chromosomal stickiness, followed by plants from Kangra $(680 \mathrm{~m})$ and Kullu $(1435 \mathrm{~m})$. Intense chromosomal stickiness was observed at M-I (Fig. 2) with clumping of the whole chromosomal complement. Interbivalent connection at M-I was among the most obvious trends in plants collected from all three localities (Fig. 5). Generally, there was normal segregation of chromosomes at A-I and A-II. Chromatin bridges were also found to be present at A-I and A-II (Fig. 3). However, the highest incidence of laggards at A-I was reported in the accession collected from Kullu (30.89\%), and the lowest in the Dalhousie population (19.27\%) (Fig. 4). SMCs also showed presence of varying number of micronuclei in all the accessions resulting from fragments and laggards (Fig. 7). During microsporogenesis, it has been observed that along with trilete spores (triangular spores with round corners), monolete, hyaline and intermediate spores were also present (Fig. 29, Table 2). Exine appears to be more or less regular. The regular size for trilete spores (Fig. 27) was $44.74 \mu \mathrm{m} \times 39.24 \mu \mathrm{m}$. Spore fertility was estimated through the stainability test, and $24-32 \%$ of the spores was found to be sterile with unstained or poorly stained shriveled cytoplasm (Fig. 30).

\section{Triploid apogamous}

Triploid cytotype was collected from the Bathri area $(1720 \mathrm{~m})$ in Dalhousie, a town of Himachal Pradesh. This cytotype has highly irregular meiotic course (Table 1). Meiotic examinations revealed the presence of 87 bivalents at M-I $(2 n=3 n=87)$ (Fig. 8). The presence of one B-chromosome at diakinesis (Fig. 25) and M-I (Fig. 26) was noticeable information for this species. Along with normal bivalents, few univalents were also found at M-I (Figs. 9, 10). Laggards were observed at A-I (Fig. 13) as well as at A-II (Fig. 14), where few chromosomes were lagging behind. The presence of unoriented bivalents at M-I was also observed, where two or more bivalents failed to orient themselves at the equatorial plate (Fig. 11). Anaphasic and telophasic bridges (Fig. 15) have been observed in a number of SMCs $(14.45 \%)$, along with other abnormalities such as early disjunction (Fig. 12) and late disjunction. Micronuclei formation was the most noticeable happening in the plants (Figs. 16-22). In addition to regular tetrad formation, there is formation of triads (Fig. 23) and polyads with or without micronuclei (Fig. 24). Monolete spores as well as trilete spores, along with intermediate and hyaline spores, were observed (Figs. 28, 31). The average size for apparently fertile trilete spores was $45.34 \mu \mathrm{m} \times 40.92 \mu \mathrm{m}$. A good number of spores were abortive and had irregular shapes (Fig. 32, Table 2).

\section{Discussion}

Apomixis is quite common in ferns. Walker (1979) estimated that nearly $10 \%$ of all the leptosporangiate ferns are agamosporous. In apomictic ferns, there is failure of mitotic anaphase at the pre-meiotic stage, resulting in doubling of chromosomes. According to Manton (1950), such eight cells are directly transformed into spore mother cells and show normal pairing due to the presence of two entirely homologous sets of chromosomes and show 32 spores per sporangium. The apogamy is mostly judged by reproductive biology characteristics 


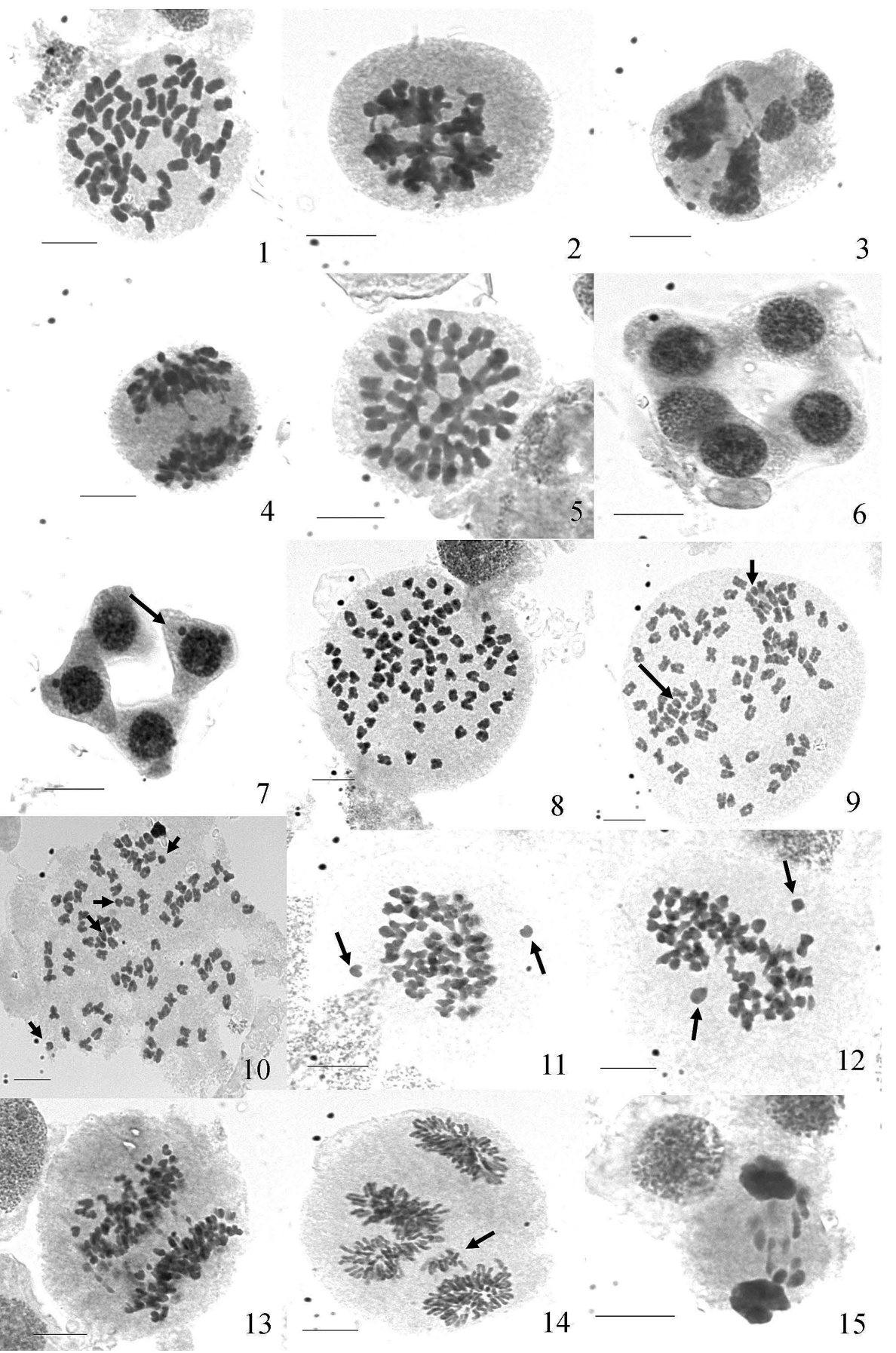

Figs. 1-15. Diploid cytotype: 1) SMC with $58_{\text {II }}$ at M-I (RS). 2) Intense chromatin stickiness at M-I (SH). 3) Chromatin bridges at A-II (RT). 4) Laggards at A-I with mild chromatin stickiness (SH). 5) Interbivalent connections at M-I (RT). 6) A polyad (RS). 7) Micronuclei at quartet stage (RS). Triploid cytotype (BT): 8) SMC with 87 II at M-I. 9) SMC with $86_{\mathrm{II}}+2_{\mathrm{I}}$ at M-I. 10) SMC with $85_{\mathrm{II}}+4_{\mathrm{I}}$ at M-I. 11) Two unoriented bivalents at M-I. 12) SMC at M-I showing early disjunction of bivalent. 13) Laggards at A-I with mild chromatin stickiness. 14) SMC with laggards at A-II. 15) Bridge formation at T-I.

such as ploidy level, spores per sporangium, spore size, etc. (Huang et al. 2011). The phenomenon of apomixis is observed in all four presently studied populations of P. cretica. The three populations with 58 bivalents at diakinesis/M-I are diploid apomicts, while the one population with 87 bivalents is triploid apomicts. Mehra and Verma (1960) observed that triploid apomicts produce bivalents in all eight spore mother cells per sporangium with normal meiotic stages. Presently, the apomictic triploid population, $P$. cretica, showed normal 87 bivalent formation but had abnormal meiosis. The present record of diploid and triploid chromosomal races in $P$. cretica is in line with earlier reports from western and central Himalayas (Mehra and Verma 1960, Verma and Khullar 1965a, b, Verma and Golaknath 1967, Khullar and Mehra 1972, Jha and Sinha 1987, Khullar et al. 


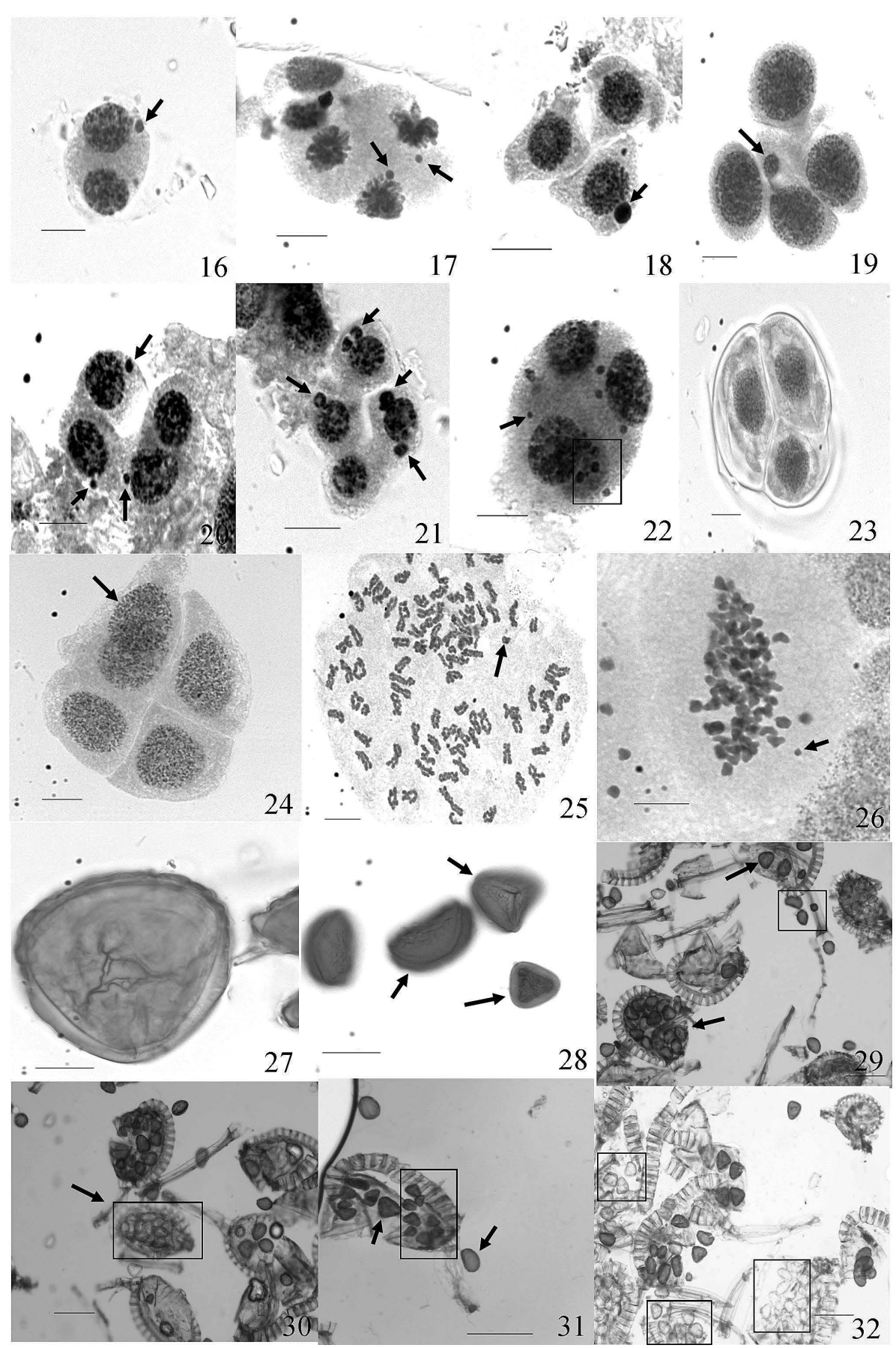

Figs. 16-32. Triploid cytotype: 16) Micronuclei formation at T-I stage. 17) SMC with two micronuclei at T-II stage. 18) Triad with micronuclei. 19) Tetrad with micronuclei. 20) SMC with three micronuclei (smaller in size) at quartet stage. 21) Tetrad with five micronuclei (bigger in size). 22) Maximum count for micronuclei, i.e., 11 with one, of very small size (arrowed). 23) A triad. 24) A polyad. 25) SMC at Diakinesis showing $87_{\mathrm{II}}+1 \mathrm{~B}$ chromosome. 26) SMC at M-I with B-chromosome. 27) Apparently fertile, trilete spore with triradiate ridge at 100X (Diploid cytotype, RT). 28) Trilete, monolete and intermediate spores at 40X (Triploid cytotype). 29) 16 celled-sporangia with trilete and intermediate spores of diploid cytotype (RN) at 10X. 30) Hyaline and monolete spores in diploid cytotype $(\mathrm{SH})$ at 10X. 31) 16 celled-sporangia showing trilete, monolete and intermediate spores of triploid cytotype at 10X. 32) Abortive sporangia with hyaline spores in triploid cytotype at $10 \mathrm{X}$. SMC $=$ Spore mother cell, RS=Raison, $\mathrm{SH}=$ Summer Hill, $\mathrm{RT}=$ Ranital, BT=Bathri. Scale bar $=10 \mu \mathrm{m}$.

1988).

All the apogamous taxa investigated during the present study revealed a number of cytological abnormalities. Stickiness has been reported to be result of partial dissolution of nucleoproteins and alteration in the pat- tern of organization of chromosomes (Evans 1962) or due to disturbances in cytochemically balanced reactions (Jayabalan and Rao 1987). In the present study, the whole chromosome complement seemed to be interconnected, forming interbivalent connections. It is 
Table 2. Microsporogenesis of diploid and triploid cytotypes, i.e., percentage of different types of spores and spore fertility.

\begin{tabular}{lrrrcc}
\hline \hline Cytotype & Trilete & Monolete & Hyaline & Intermediate \% Fertility \\
\hline Diploid & 48.38 & 12.90 & 27.95 & 10.75 & 72.05 \\
& 51.85 & 9.87 & 24.69 & 13.58 & 75.31 \\
& 49.48 & 16.49 & 23.71 & 10.30 & 76.29 \\
Triploid & 13.18 & 8.79 & 50.54 & 27.47 & 49.46 \\
\hline
\end{tabular}

well cited in the literature that these can be associated with cytomixis or chromosomal stickiness (Singhal and Gill 1985, Thomas and Revell 1946). The laggards in a majority of the meiocytes failed to reach poles and often constituted micronuclei. The existence of laggards has been found to be highly genotype dependent (Pagliarini et al. 2000, Fuzinatto et al. 2008). Asynapsis, desynapsis, failure of chiasma formation and premature disjunction of bivalents have been proposed as possible causes (Gupta and Priyadarshan 1982). Unoriented bivalents lead to formation of laggards, divide or get eliminated as micronuclei. Non-synchronous disjunction may be due to different rates of terminalisation of various chromosomes of a complement (Darlington 1937), or absence of coordination between chromosome and spindle (Sharma 1976). Formation of triads and polyads can be attributed to failure of cytokinesis in one of the poles during A-II. As a result, spore fertility is ultimately reduced. In general, apogamous species produce two main kinds of sporangia in one of which development is normal but meiosis irregular (type 1), thereby producing abortive spores, and in the other of which the pre-meiotic mitosis is incomplete, resulting in a doubling of chromosome number and a halving of the number of spore mother cells produced (type 2). Since all the chromosomes of the latter kind of sporangium now have exact homologues, the subsequent meiosis is regular and well-filled viable spores are formed, although with the sporophytic chromosome number. So, as a consequence of meiotic abnormalities and disturbances in the process of meiosis, spore fertility was considerably decreased and heterogenous spores were produced.

Another important aspect of this study was the presence of B-chromosomes in a few SMCs. The presence of B-chromosomes at M-I can be attributed to one of the reasons for the formation of numerous micronuclei at quartet stage. B-chromosomes are known to be present in ferns such as Isoetes, Regnellidium and Ophioglossum (Goswami and Khandelwal 1980).

\section{Acknowledgements}

The authors are grateful to the University Grants Commission, New Delhi for providing facilities under DRS SAP III and ASIST programme. Financial support to Mandeep Kaur under BSR programme of UGC is gratefully acknowledged. Thanks are also due to Head,
Department of Botany for providing all the necessary laboratory facilities.

\section{References}

Chao, Y. S., Liu, H. Y., Chiang, Y. C. and Chiou, W. L. 2012. Polyploidy and speciation in Pteris (Pteridaceae). J. Bot. 2012: 1-7.

Copeland, E. B. 1947. Genera Filicum. Chronica Botanica Co., Waltham. pp. 247.

Darlington, C. D. 1937. Recent Advances in Cytology. 2nd edition. P. Blakiston's Son and Co., Philadelphia.

Evans, H. J. 1962. Chromosome aberrations induced by ionizing radiations. Int. Rev. Cytol. 13: 221-321.

Fuzinatto, V. A., Pagliarini, M. S. and Valle, C. B. 2008. Evaluation of microsporogenesis in an interspecific Brachiaria hybrid (Poaceae) collected in distinct years. Genet. Mol. Res. 7: 424-432.

Goswami, H. K. and Khandelwal, S. 1980. Chromosomal Elimination in Natural Populations of Ophioglossum. Cytologia 45: 77-86.

Gupta, P. K. and Priyadarshan, P. M. 1982. Triticale: Present status and future prospects. Adv. Genet. 21: 255-345.

Huang, Y., Hsu, S., Hsieh, T., Chou, H. and Chiou, W. 2011. Three Pteris species (Pteridaceae, Pteridophyta) reproduce by apogamy. Bot. Stud. 52: 79-87.

Jayabalan, N. and Rao, G. R. 1987. Gamma radiation induced cytological abnormalities in Lycopersicon esculentum Mill. var. Pusa Ruby. Cytologia 52: 1-4.

Jha, J. and Sinha, B. M. B. 1987. Cytomorphological variability in apogamous populations of Pteris cretica L. Caryologia 40: 71-78.

Khullar, S. P. and Mehra, P. N. 1972. Cytotaxonomy of W. Himalayan ferns: 3. Polypodiaceae (sensu stricto). Nucleus 15: 156-162.

Khullar, S. P., Sharma, S. S. and Verma, S. C. 1988. SOCGI plant chromosome number reports: VI. J. Cytol. Genet. 23: 38-52.

Kramer, K. U. and McCarthy, P. M. 1998. Flora of Australia: Ferns, Gymnosperms and Allied Groups. Australian Biological Resources Study, Collingwood.

Manton, I. 1950. Problems of Cytology and Evolution in the Pteridophyta. Cambridge University Press, London.

Mehra, P. N. and Verma, S. C. 1960. Cytotaxonomic observations on some West Himalayan Pteridaceae. Caryologia 13: 619-650.

Mitui, K. 1965. Chromosome studies on Japanese ferns (1). J. Jpn. Bot. 41: 117-124.

Nakaike, T. 1984. New Flora of Japan: Pteridophyta. Shibundo Co., Ltd., Tokyo. (in Japanese)

Nakato, N. 1975. A cytological study on an intermediate form between Pteris multifida and P. cretica. J. Jpn. Bot. 50: 110-125. (in Japanese)

Nakato, N. 1989. Distributions and fronds variations in diploid and triploid cytotypes in Pteris cretica L. in Kanto District. J. Phytogeo. Taxon. 37: 113-119. (in Japanese)

Pagliarini, M. S., Frietas, P. M. and Batista, L. A. R. 2000. Chromosome stickiness in meiosis of a Brazilian Paspalum accession. Cytologia 65: 289-294.

Sharma, A. K. 1976. The Chromosomes. Oxford and IBH Pub. Co., New Delhi.

Singhal, V. K. and Gill, B. S. 1985. Cytomixis in some woody species. Biologica 1: 168-175.

Suzuki, T. and Iwatsuki, K. 1990. Genetic variation in agamosporous fern Pteris cretica L. in Japan. Heredity 65: 221-227.

Thomas, P. T. and Revell, S. H. 1946. Secondary association and heterochromatic attraction: I. Cicer arietinum. Ann. Bot. 10: 159-164.

Verma, S. C. and Golaknath, M. 1967. In: Love, A. (ed.). IOPB Chromosome number reports XIV. Taxon 16: 552-571.

Verma, S. C. and Khullar, S. P. 1965a. Cytology of some W. Himala- 
yan Adiantaceae (Sensu Alston) with Cytotaxonomic Comments. Caryologia 18: 85-106.

Verma, S. C. and Khullar, S. P. 1965b. Cytogenetics of the western Himalayan Pteris cretica complex. Ann. Bot. 29: 673-681.

Walker, T. G. 1962. Cytology and evolution in the fern genus Pteris, L. Evolution 16: 27-43.

Walker, T. G. 1979. The Cytogenetics of Ferns. In: Dyer, A. F. (ed.).
The Experimental Biology of Ferns. Academic Press, New York. pp. 87-132.

Walker, T. G. 1992. The genus Pteris, its breeding systems and its horticultural potential. In: Ide, J. M., Jermy, A. C. and Paul, A. M. (eds.). Fern Horticulture: Past, Present and Future Perspectives. Proceedings of an International Symposium on the Cultivation and Propagation of Pteridophytes, London. pp. 195-207. 